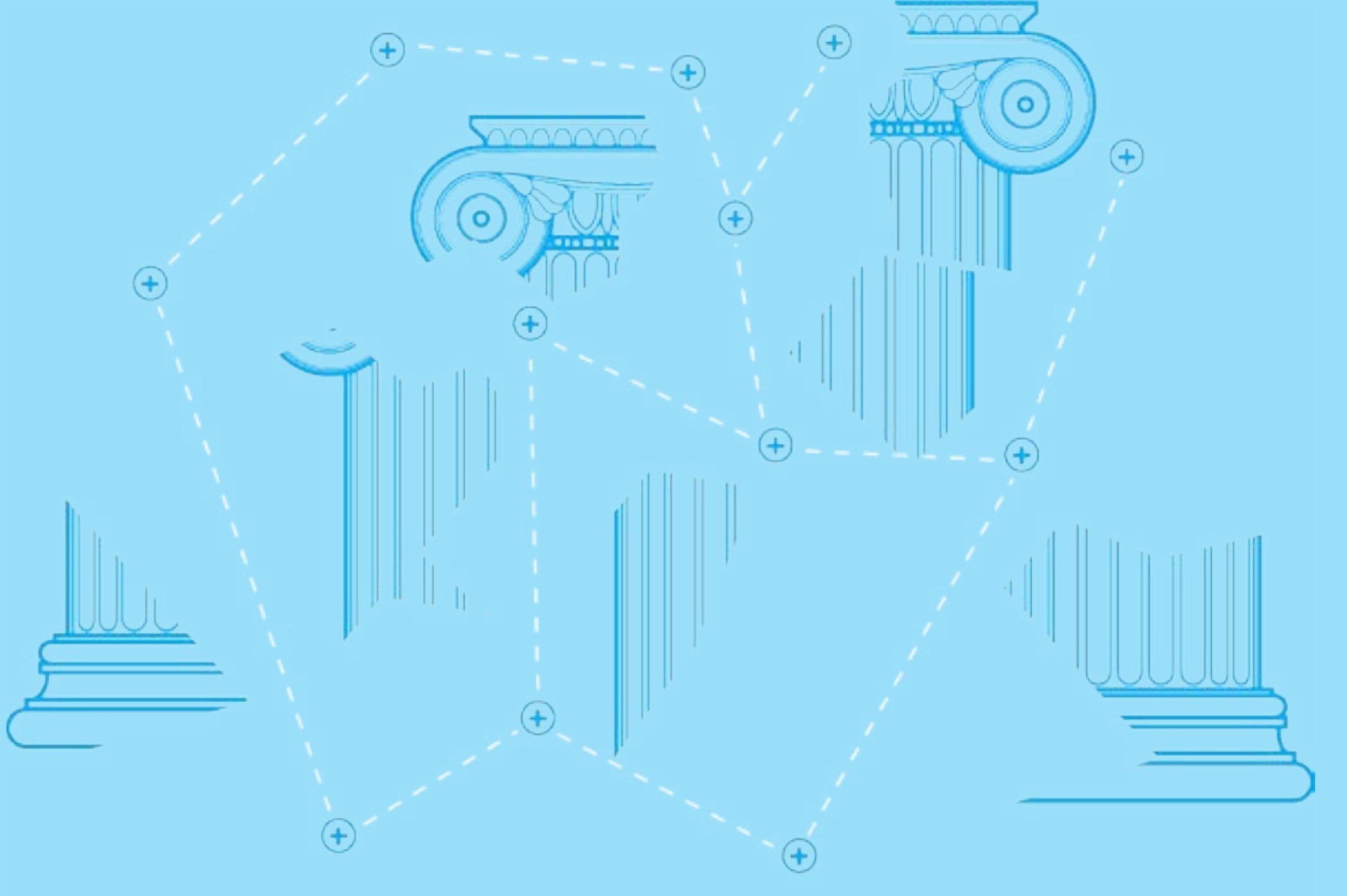

\title{
El maestro y la maestra, como productores de saber y conocimiento, refundamentan el saber escolar en el siglo XXI
}

The teachers, as producers of wisdom and knowledge re-think school knowledge in the XXI century

O professor, como produtores de conhecimento e conhecimento sediada conhecimento escolar no século XXI 
El maestro y la maestra, como productores de saber y conocimiento, refundamentan el saber escolar en el siglo XXI (Documento en construcción) ${ }^{2}$

\section{Marco Raúl Mejía}

Doctor Programa Interdisciplinar Investigación en Educación. Proyecto Interdisciplinario en Investigaciones Educativas. Maestría en Desarrollo Educativo y Social, CINDE. Licenciatura en Filosofía y Letras, Pontificia Universidad Javeriana. Trabaja en Planetapaz / Expedición Pedagógica / Movilización Social por la Educación.

1 Dedico este texto, que sigue en construcción, a las maestras y maestros del Programa Ondas de Colciencias, la Expedición Pedagógica Nacional y la Movilización Social por la Educación; libros vivos que han alimentado mi vida y mis producciones en los últimos doce años.

2 Apartes del material elaborado para MOVA -Centro de innovación del maestro de la Secretaría de Educación de Medellín y Explora. El primer borrador se presentó en el Seminario de educación e investigación, programado por ADIDA, la Secretaría de Educación y otras entidades de la ciudad de Medellín, del 6 al 8 de octubre de 2014; su origen fue un documento elaborado durante las reflexiones del Programa Ondas, la Expedición Pedagógica y la Movilización social por la educación; publicado en Mejía, Marco Raúl. "El maestro investigador: reconstructor de sentido profesional e identidad". Revista $P A C A$. No. 1, Junio. Neiva. Universidad Surcolombiana. 2009.

Fecha de recepción: 16 de marzo 2015 / Fecha de aprobación: 3 de abril de 2015.

\section{Resumen}

Esta investigación presenta caminos y perfiles muy claros, con los cuales el maestro y la maestra, en tanto productores de saber y conocimiento, se ven en la obligación de reformular críticamente su manera de ser docentes aquí y ahora, contando con las características de un mundo globalizado que se transforma y que al hacerlo implica modificaciones profundas en los procesos inherentes a las prácticas disciplinares y las profesiones. Por ello, el planteamiento básico del presente texto es que es necesario aprovechar la discusión sobre la ciencia y la investigación, para reposicionar al maestro como sujeto investigador a partir, en y desde su práctica, lo cual requiere de una serie de desplazamientos en la forma de entender su condición, su quehacer y su investigación.

Palabras clave:

Práctica pedagógica, investigación, MOVA, maestro investigador, ONDAS, saber docente.

\section{Summary}

This research presents very clear paths and profiles, with which the teacher and the teacher, as producers of knowledge and understanding, are obliged to critically rethink the way they are teaching here and now, with the features of a world which becomes globalized and in doing so involves profound changes in the processes involved in disciplinary practices and professions. Therefore, the basic approach of this text is that it is necessary to take the discussion on science and research, to reposition the teacher as a research subject from in and from practice, which requires a series of journeys in the form to understand their condition, their work and research.

\section{Key words:}

Teaching practice, research, MOVA, researcher, ONDAS, teacher knowledge.

\section{Resumo}

Esta pesquisa apresenta caminhos muito claros e perfis, com o qual o professor eo professor, como produtores de conhecimento e compreensão, são obrigados a repensar criticamente a forma como eles estão ensinando aqui e agora, com as características de um mundo que se torna mais globalizado e ao fazê-lo envolve mudanças profundas nos processos envolvidos em práticas disciplinares e profissões. Portanto, a abordagem de base deste texto é que é necessário levar a discussão sobre ciência e investigação, para reposicionar o professor como sujeito de pesquisa a partir de dentro e de prática , $\mathrm{O}$ que exige uma série de viagens na forma para entender sua condição, o seu trabalho e pesquisa.

Palavras chave:

Prática pedagógica, pesquisa, MOVA, professor pesquisador, ONDAS, saber professor. 


\begin{abstract}
"La mayoría de los científicos no están conscientes de las implicaciones epistemológicas y ontológicas de lo que hacen, porque para ellos ciencia es un dominio de praxis y no un dominio de reflexiones. Algo similar acontece a muchos filósofos que no entienden qué ocurre en la ciencia, porque para ellos ciencia es un dominio de reflexiones y no un dominio de praxis".
\end{abstract}

Humberto Maturana ${ }^{3}$.

$\mathrm{M}$ aturana ubica en este desencuentro, muy propio de la cultura occidental, las dificultades implícitas en la interpretación reduccionista de la ciencia; aquella que parte de pensar que la explicación expresa lo fundamental del fenómeno y que su validez depende de las referencias, directas o indirectas, a una realidad objetiva de la cual el observador es independiente. Este tipo de análisis hace que el carácter generativo de las explicaciones científicas no sea visto en muchas investigaciones, porque quienes investigan creen, implícita o explícitamente, en una validación fundada en la objetividad, en donde las afirmaciones y explicaciones son legítimas por ser independientes del sujeto que las hace.

Esta pequeña introducción me permite exponer mi hipótesis central: deben ser aprovechadas las modificaciones que se vienen dando en la idea de ciencia y de investigación para salir de las dualidades que han limitado el hecho investigativo del maestro, ya que es corriente escuchar a muchas personas decir que el maestro es un enseñante, que su oficio es la formación, que su saber no produce conocimientos, que sus procedimientos no se atienen a los del método científico.

Creo que los cuestionamientos y los replanteamientos que se vienen haciendo al respecto son muy propicios para construir un espacio en el cual el maestro y la maestra construyan una identidad como investigadores. En este sentido, exploraré la forma en que el hecho investigativo, que no pierde su rigor, es replanteado en una discusión que hoy tiene lugar en las diferentes disciplinas e interpretaciones de la ciencia y la investigación. Por ello, intentaré mostrar cómo los elementos críticos del debate contemporáneo sobre la ciencia dan unos cambios que abren las puertas para una reflexión sobre la investigación en la especificidad del saber pedagógico.

3 Maturana, H. (1997). La objetividad, un argumento para obligar. Santiago de Chile: Editorial Dolmen, p. 35

\section{Comprendiendo los cambios de época y civilizatorios ${ }^{4}$}

Uno de los asuntos centrales para cualquier actor de esta sociedad es el de dar una explicación teórica, con incidencia práctica, de los cambios que acontecen en nuestras realidades y del impacto que ellas han tenido en nuestras prácticas, conceptualizaciones y explicaciones de la sociedad inmediata y del mundo que vivimos. Desde múltiples lugares se ha llegado a una especie de acuerdo común sobre esos elementos que han configurado las transformaciones de este tiempo y que cada quien elabora, según sus énfasis profesionales, colocando la importancia de acuerdo a sus intereses específicos. Un ejemplo emblemático es el del premio Nobel de Física, Georges Charpak, quien concluye que asistimos a una "[...] mutación histórico social" semejante a la que se vivió en los comienzos del Neolítico hace 12.500 años. En nuestro contexto, Barbero diría:

Nos enfrentamos así a otro cambio mucho más radical, consistente en los nuevos modos de producción del conocimiento y más específicamente a las nuevas relaciones entre lo sensible y lo inteligible. Ahí reside la lucidez de Castells, quien ata la mutación digital a la superación definitiva de la separación entre los dos lóbulos del cerebro: el de la razón argumental y el de la emoción pasional, ¡Que por mera casualidad resulta ser el del arte! Pues bien, hoy día a lo que en las ciencias clave como la física y la biología se llama cada día más frecuentemente 'experimental', es a simular digitalmente en computador ${ }^{5}$.

Existe un acuerdo que permite entender que esos elementos configuradores de este tiempo-espacio actual, son: el conocimiento, la tecnología, los nuevos lenguajes, la información, la comunicación, la innovación y la investigación.

4 Tomado de: Apartes del documento de Mejía, M. R. Pensar el humanismo en tiempos de globalización. Ponencia presentada al congreso congregacional de las Hermanas Franciscanas sobre Educación Cristiana en el Siglo XXI. Medellín, 16 al 18 de agosto de 2014. Ampliación del documento presentado al congreso de Humanismo y Globalización de la Universidad Francisco de Paula Santander. Cúcuta. Septiembre 24-26 de 2004. Inédito. Citado por: Equipo coordinador Instakids. Propuesta de formación del equipo pedagógico de FITEC. Bogotá. 2015. Inédito.

5 Martín-Barbero, J. (2007). ¿Razón técnica vs. razón pedagógica? En Zuleta, M., Cubides, H., y Escobar, M. R. (Eds.). ¿Uno solo o varios mundos? Diferencia, subjetividad y conocimientos en las ciencias sociales contemporáneas. Bogotá. Universidad Central, IESCO, Siglo del Hombre Editores, p. 215. 
1. El conocimiento. Está configurado en el paradigma científico de la modernidad capitalista que funda el Modo 1 de la ciencia (Copérnico, Descartes, Galileo, Newton, Hobbes), su replanteamiento a lo largo del siglo XX dio lugar al Modo 2 de la ciencia (Heisenberg, Einstein, Planck, Peat), el cual ha sido el factor básico de las modificaciones estructurales de la sociedad en los últimos años.

2. La tecnología. La cual hace su tránsito desde la técnica, relacionándose con el nuevo tipo de conocimiento al generar procesos en donde la relación teoría-práctica se modifica a través de las cuatro edades de la máquina: la del vapor, la de los motores eléctricos, la electrónica y la de la microelectrónica e informacional.

3. Nuevos lenguajes. La base de los cambios en los dos aspectos anteriores fue el surgimiento del nuevo lenguaje digital en la historia de la humanidad, el cual, unido al escrito y al oral hace más complejas las formas de la cultura y establece una serie de cambios socio-metabólicos que inciden en las nuevas creaciones culturales y en las relaciones generacionales.

4. La información. Se convirtió en un elemento central en los procesos que reorganizan y reestructuran las formas del conocimiento, ya que es clave para el funcionamiento de todo el sistema de máquinas y tecnológico, así como de los aspectos de la producción convertidos en servicios. La información se hace complementaria y diferente al conocimiento.

5. La comunicación. Las nuevas realidades de la tecnología y la información permitieron la aparición de infinidad de procesos mediados en su mayoría por la imagen, generando dinámicas culturales sobre nuevos soportes y una producción que ha llevado a construir de otra manera los procesos de socialización y las dinámicas de la industria cultural de masas.

6. La innovación. Es uno de los elementos que ha tomado mayor preponderancia en las actuales transformaciones. La velocidad del cambio en el conocimiento, ligada a la producción permanente de nuevos productos, ha hecho de este aspecto uno de los ejes de discusión y le hace importante en las empresas, la educación, las tecnologías y en las diferentes dinámicas de la sociedad.

7. La investigación. Se ha convertido en uno de los factores básicos de las transformaciones contemporáneas; se ha constituido como un campo de saber y ha configurado nuevas realidades sobre las que se tejen parte de los cambios estructurales del poder en la sociedad actual.

8. Crisis civilizatoria. El sistema-mundo que se organiza a partir de realidades anteriores tuvo una crisis profunda y una reorganización de múltiples sentidos; los supuestos del mundo eurocéntrico comienzan a ser cuestionados y se da un replanteamiento de la manera como el ser humano se relaciona con la naturaleza, esto comienza a mostrar los límites de las teorías basadas en el crecimiento como una única posibilidad de organizar la sociedad. En ese sentido, emergen con fuerza las crisis políticas derivadas de la multipolaridad y sus influencias sobre la humanidad; la situación no solo ha sido resultado de un cambio de época, sino que se relaciona con el hecho de que ya no estamos frente a un solo centro del conocimiento. Ahora ese centro está en medio de una crisis estructural que afecta a las ideas principales de la organización de la sociedad capitalista:

- Una economía basada sobre el crecimiento infinito.

- Una naturaleza entendida como estar ahí para ser dominada por lo humano.

- Una idea de progreso sin fin.

- Unas epistemologías basadas en lo universal y en la negación de la diferencia.

- Una idea de desarrollo que plantea el subdesarrollo para, de allí, determinar la organización de todos los organismos multilaterales.

Este mundo ha dejado clara la inviabilidad de este proyecto centrado en el dominio unipolar, en la eliminación de la diversidad y en el uso indiscriminado de los recursos, llegando a demostrarse claramente bajo las formas de las crisis financieras, climáticas, energéticas y de alimentos, entre otras que encontra- 
mos en los diarios, las revistas especializadas y los artículos de expertos.

Con esta apretada síntesis, dejamos abierto un problema que está en la base de la constitución de la sociedad actual, que re-articula su organización, los procesos de relaciones y aquellos que construyen nuevas formas de control, generando una sensación de novedad que pareciera dejar atrás la manera en que se ha ejercido el poder. Las lecturas que son fruto de esta visión hacen ver los cambios en el desarrollo de la sociedad como si se tratara de dinámicas neutras, en donde el conocimiento y la tecnología hubiesen llegado a un nivel máximo de su evolución produciendo una transformación de la sociedad anunciada en un nuevo lugar del consumo.

La particular manera de nombrar estos cambios hace el énfasis en el elemento visible que los constituye: "sociedad del conocimiento", "sociedad de la información", "la tercera ola", "sociedad informacional", "sociedad posindustrial", "sociedad tecno-científica", "sociedad posmoderna”, etc. Estas denominaciones dan cuenta de algunos de los factores que dinamizan las modificaciones en marcha; sin embargo, se olvida que todo se da en medio de unas relaciones de poder y de reconfiguración de los procesos de control, que vuelven a generar desigualdad e inequidad en la sociedad, reestructurando el proceso de acumulación del capital ${ }^{6}$. Así, es necesario ir más allá en el análisis, pues no solo estamos ante unas transformaciones de época y de civilización, sino que enfrentamos un cambio en la forma del control capitalista, lo cual exige nuevas interpretaciones y, por lo tanto, nuevas formas de resistencia.

A lo largo del siglo XX, el planteamiento de una única manera de entender la ciencia, que había tenido su clímax en el Círculo de Viena con el denominado positivismo lógico, fue sufriendo grandes replanteamientos desde múltiples lugares. Por ejemplo, en el lenguaje (Wittgenstein), la filosofía, Escuela de Frankfurt (Adorno), la lógica (Popper), la física (Hesinberg), la historia de la ciencia (Kühn, Serrés), etc. También surgieron cuestionamientos frente al argumento de que la teoría y la experimentación eran la una única manera de entender la realidad; frente a ellas, las explicaciones y comprensiones desde la acción mostraban otra posibilidad.

Este nuevo lugar para mirar la realidad significó también el reingreso del sujeto a la investigación, de la cual había sido ex-

6 Meszaros, I. (2009). El desafío y la carga del tiempo histórico: El socialismo del siglo XXI. Caracas: Fundación Editorial El perro y la rana. pulsado desde Descartes, lo cual trajo como consecuencia la emergencia de diferentes métodos y explicaciones, desde variadas perspectivas, para abordar el asunto de la producción de saber y conocimiento. Ello produjo una salida de una única manera de entender las elaboraciones de la ciencia, su pluralización y un camino metodológico diverso.

\section{Incidencia y replanteamiento en educación ${ }^{7}$}

En el ámbito educativo entró en crisis la versión del proceso-producto, que considera la enseñanza como la causa del aprendizaje. Se propusieron enfoques holísticos orientados en las metodologías bíbridas que combinan lo cuantitativo y lo cualitativo, resaltando la necesidad de desarrollar metodologías que tengan en cuenta los contextos y la vida de los participantes de la actividad escolar. Esto conlleva a que algunas posiciones críticas no busquen, en la actividad escolar, procesos curriculares que trasladen la lógica de la disciplina cientifica a la escuela, sino que busquen integrar las diferentes dimensiones del desarrollo bumano, en el proceso educativo, y no solo en lo conceptual.

Se sumaron grupos y personas que buscaban una correlación de las ciencias naturales con la cultura, lo que llevó a algunos autores a hablar de una tercera cultura de la ciencia (Morin). Así, se buscó en la educación la diferencia entre la lógica del conocimiento cientifico y el escolar. Los planteamientos a esta problemática son de interés mundial, y son tema en común para autores, como Toulmin ${ }^{9}$ (inglés); Porlan ${ }^{10}$ (español) y Vasco $^{11}$ (colombiano). Luego de esto, se revaloró la actividad escolar como una actividad cualificada del conocimiento, y no solo como una entidad de transmisión de él.

Emergió, entonces, una escuela focalizada en lo cognitivo, que reconoce la ética, la estética y la capacidad crítica para trans-

7 Texto tomado de Mejía y Manjarrés. (2009). Informe de la reconstrucción colectiva del Programa Ondas. Búsquedas de la investigación como estrategia pedagógica. Periodo 2006-2008. Bogotá: Colciencias-Programa Ondas, Fundación FES Social, pp. 140-147.

8 Morin, E. (1994). El método, Tomos I, II, y III. Madrid: Cátedra, p. 245

9 Toulmin, S. (1977). La racionalidad humana, el uso colectivo y la evolución del concepto. Madrid: Alianza.

10 Porlan, R., y Martín, R. (1998-Febrero). Conocimiento profesional y epistemología de los profesores. Estudios empíricos y conclusiones en enseñanza de las ciencias. Cuadernos de Pedagogía, pp. 271-288.

11 Vasco, C. E. (1989). Convergencias acerca de la pedagogía de las ciencias naturales. Revista Educación y Cultura, No. 19. 
formar su entorno y la vida. El ideal es hacer de ella un lugar donde se estructuren y consoliden los conocimientos científicos, los normativos y los que cada generación considere fundamentales como valores para su vida presente y futura.

A la luz de estos replanteamientos, se gesta la búsqueda de caminos conceptuales y metodológicos apropiados para aprender, en coherencia con la discusión, y el desarrollo del pensamiento cientifico del siglo XX. Se abre pues un debate sobre los aspectos que entran en juego en los procesos escolares. Dice Hodson:

El fracaso de los cursos de ciencias modernas en lograr algunos de sus objetivos declarados, en relación con la comprensión de los niños sobre la naturaleza de la ciencia, se debe, en parte, a un grado de confusión en la posición filosófica sobre la que se asientan muchos currículos contemporáneos, y, en parte, al continuo fracaso en proporcionar a los profesores una comprensión adecuada de cuestiones básicas en filosofía de la ciencia, y su importancia en el diseño de experiencias de aprendizaje. En muchos currículos de ciencia se pone demasiado énfasis en los métodos inductivos, una aceptación demasiado rápida de un punto de vista instrumentalista de la teoría científica, una seria subestimación de la compleja relación entre la observación y la teoría y un abandono de las actividades de la comunidad científica, al validar y diseminar el conocimiento científico ${ }^{12}$.

En el marco de estas discusiones, surge una modificación en el entendimiento de la actividad cientifica en el mundo de la educación y de la escuela, y su especificidad se da al lado de los otros tres ámbitos propios de ella, los cuales están en permanente interacción:

1. La innovación.

2. Su justificación (filosofía).

3. Su aplicación.

4. Su enseñanza.

En esta última, se desarrollan los conocimientos cientificos normativos. Son aquellos que cada colectivo bumano considera importantes para que niñas, niños y jóvenes puedan reconocer $e$ incorporarse al grupo disciplinario. Como sostiene Guidoni, el

12 Hodson, D. (s.f.). Filosofía de la ciencia y educación científica, Philosophy of Science and Science Education. Journal of Philosophy of Education, Vol. 20, No. 2.

Educación y CIudad No 29 Julio - Diciembre de 2015 ISSN 0123-0425 - PP 16 - 38 conocimiento, la experimentación y el lenguaje interactúan para transformar el mundo. Así, no se puede situar la ciencia en la enseñanza sin tener en cuenta la mediación de los instrumentos y del lenguaje. Por ello, ciencia y técnica deben verse estrechamente relacionados.

Si la ciencia tiene varios enfoques sobre los que puede ser abordada, según el ámbito en el que se trabaje, la enseñanza, como uno de ellos, debe tener la meta, el método y su campo de aplicación en coherencia con el mundo de la escuela. Esto construye una estructura del conocimiento escolar con cuatro componentes: el mundo de los alumnos, los fines de la escuela (su proyecto), la ciencia para este contexto y el método para lograr el resultado.

En este punto aparecen el maestro y la maestra; estos, como mediadores, son responsables de introducir al niño y al joven en el mundo de lo científico, buscando que éste dé el paso en su vida cotidiana hacia la comprensión del mundo y lenguaje cientificos. Por ello, no basta con que el maestro o maestra sepa de ciencia, es necesario que sepa cómo mediar para construir aprendizajes reales en la vida de sus estudiantes. Visto así el hecho científico, entendido desde el ámbito de la enseñanza y el aprendizaje, lleva a pensar el proceso escolar desde la interacción entre la enseñanza de la ciencia y los otros contextos de la actividad científica.

Esto significa que los modelos científicos están implícitos en los enfoques de aprendizaje y, por lo tanto, deben ser explicitados, ya que ese modelo de enseñanza y aprendizaje genera un entendimiento y una manera de valorar el lugar de la ciencia en la sociedad. Es este el núcleo central de los diferentes enfoques para la enseñanza de las ciencias, ya que alli están sintetizadas todas las concepciones y discusiones planteadas en las páginas anteriores.

Por esta razón, el papel del maestro y su concepción de ciencia ligada a la pedagogía es primordial en la acción escolar. Esto genera campos de saber, y estudiantes y maestros que actúan como agentes centrales de la reconstitución de la ciencia en el mundo de la educación. Este nuevo debate llevó a Bruner ${ }^{13}$ a afirmar que las dificultades que los seres humanos de nuestro tiempo tienen para comprender las matemáticas y las ciencias surge, no por la falta de capacidades, sino porque no se logra encontrar un camino adecuado que facilite usar el conocimiento para explicar fenómenos cotidianos. Los estudiantes no usan los conceptos, no entienden el funcionamiento de las máquinas con las que interactúan todos los días. Además, la enseñanza de la ciencia se ha vuelto aburrida y exige la búsqueda de procesos pedagógicos adecuados para los jóvenes y las nuevas realidades.

13 Bruner, J. (1987). La importancia de la educación. Barcelona: Paidós. 
Esto conlleva un cambio a la idea del maestro y su rol. Para muchos era darle lugar a modelos de conocimiento más abiertos, pero con la misma estructura unilineal y secuencial del conocimiento científico-escolar. Aparecen, también, criticando esta visión, los autores que buscan a ese maestro capaz de relacionarse con una disciplina que ya no consiste en repetir un camino prefijado. A la luz de estas miradas, surgen múltiples concepciones, por ejemplo, la de Schön ${ }^{14}$ que los reconoce más como productores de saber, que como implementadores de procesos prediseñados, y los denomina "profesionales reflexivos". Su discurso muestra cómo la relación teoría-práctica se da también con la especificidad del saber pedagógico, lo que contribuye a una relación diferenciada entre él y el saber disciplinario. Esto, a su vez, especifica al saber docente.

Por otro lado, Perrenoud ${ }^{15}$ muestra cómo desarrollar la práctica reflexiva en el oficio de enseñar. Para ello, escenifica y rehace, con especificidad, prácticas pedagógicas complejas con saberes, procedimientos, actitudes, rasgos de personalidad, componentes de condición física y mental y esquemas de acción de hábitos.

De igual manera, Cochran [-Smith] y Lytle ${ }^{16}$ y Martín plantearon la existencia de conocimientos y reflexiones en la acción, presentes en las actuaciones explicitas e implicitas. Cuestión que permite integrar lo cognitivo, lo emocional, la teoría y la práctica, reconociendo que los docentes y los aprendices de ese oficio trabajan dentro de una comunidad para generar conocimiento local, prever su práctica y teorizar sobre ella, interpretando las investigaciones y conclusiones de otros. En este sentido ese trabajo es entendido politicamente, ya que implica el cuestionamiento de los procedimientos actuales de la escolarización, de los modos en que se construye, se evalúa y se usa el conocimiento, asi como la forma de los roles individuales y colectivos de los maestros y maestras en el momento de hacer reales los cambios, generando un conocimiento local-público propio de la práctica profesional del docente.

A la luz de estas reflexiones, en diferentes paises se desarrollaron grupos reconocidos para investigar estos procesos

14 Schön, D. (1991). La formación de profesionales reflexivos. Hacia un nuevo diseño de la enseñanza y el aprendizaje en las profesiones. Madrid: Paidós.

15 Perrenoud, P. (2004). Desarrollar la práctica reflexiva en el oficio de enseñar. Profesionalización y razón pedagógica. Barcelona: Grao.

16 Cochran, M., y Lytle, S. (2003). Más allá de la certidumbre, adoptar una actitud indagadora sobre la práctica. En Liberman A., y Miller S. (Eds.) La indagación como base de la formación del profesorado y la mejora de la educación. Barcelona: Octaedro, pp. 65-79. y darles forma a esas nuevas relaciones entre conocimiento cientifico, conocimiento escolar y el lugar del maestro y la maestra en ellos; entre estos se encuentran: el Nuffield, de Gran Bretaña, y el Grupo de Investigación en Integración Educativa (GRINTIE), español, el de Tucson (Arizona), así como muchos otros en diversas naciones, los cuales realizan un énfasis en la mirada interdisciplinaria.

En Colombia, la Expedición Pedagógica Nacional retoma parte de estos planteamientos y realiza una apuesta por hacer visibles múltiples maneras de ser maestro y hacer escuela haciendo real un maestro y una maestra que pasa, de ser portador(a), a productor de saber. Existen nueve libros publicados, así como 40 videos, para el aspecto alli tratado; recomiendo el texto "Con los dedos en la filigrana”. Una lectura crítica a los tejidos metodológicos de la Expedición Pedagógica Nacional, publicado por la Universidad Pedagógica Nacional en el 200717.

De igual manera, el Programa Ondas de Colciencias elabora la propuesta de la Investigación como Estrategia Pedagógica (IEP), en la cual los niños, niñas y jóvenes construyen una cultura ciudadana y democrática en ciencia, tecnología e innovación a partir de sus preguntas convertidas en problemas, las cuales son acompañadas por sus maestras y maestros coinvestigadores $]^{18}$.

También en Colombia y algunos países de América Latina, se desarrolló el Movimiento Pedagógico, en el cual se planteó que la subjetividad del maestro y la maestra estaba dada por su condición de educador y pedagogo y, en ese sentido, era responsable de las apuestas y propuestas que desarrollaba en su quehacer cotidiano; cuando esta corriente llega al sindicato construyó un discurso y una práctica político-pedagógica que, en el caso de Colombia, fue liderada por la Federación Colombiana de Educadores (Fecode). $(255)^{19}$

En el marco de esta discusión, surgen infinidad de propuestas para solucionar el problema de la metodología en los procesos de aprendizaje. Todo depende de cómo la propuesta pedagógica retome la discusión y la sitúe en el escenario escolar, otorgando su

17 Para mayor información se puede consultar www.expedicionpedagogica.org

18 Programa Ondas. (2012). Niños, niñas y jóvenes investigan. Lineamientos pedagógicos del Programa Ondas. Bogotá: Colciencias Programa Ondas, Fundación FES Social. Para ver todos los materiales, se recomienda visitar la biblioteca virtual del Programa Ondas: http:// www.colciencias.gov.co/sites/default/ files/Ondasfinal/index.html

19 Mejía, M. R. (2006). Los movimientos pedagógicos en tiempos de globalización. Globalizaciones y Educaciones. Entre el pensamiento único y la nueva crítica. Bogotá: Ediciones Desde Abajo, pp. 287-323. 
lugar a los diferentes actores, y de que el desarrollo de las posibles opciones metodológicas permita, de acuerdo al contexto de cada particularidad, optar por uno u otro camino para resolver la estrategia metodológica.

Se conforman, pues, apuestas contextuales, sociales, holisticas y críticas sobre cómo resolver esta discusión, educativa, social y metodológicamente. Se debe reconocer que el uso de la investigación o indagación como metodología para construir un espiritu cientifico en niñas, niños y jóvenes ha abierto múltiples caminos con diferentes procesos para desarrollar.

Esta movilización en el pensamiento y en la acción, determinada por la práctica de los actores, fue haciendo visible a un maestro y una maestra que se veían como productores de saber y conocimiento, todo en la medida en que se fueron implicando en búsquedas innovativas para dar respuesta, desde su práctica, a las nuevas exigencias derivadas de los replanteamientos que trazaban un nuevo contexto como dimensión de la realidad, unos nuevos principios para la ciencia, el conocimiento, las pedagogías y sus dispositivos de acción.

Una línea metodológica que trata de dar salida al debate contemporáneo sobre la ciencia y su incidencia en la educación, implica usar la investigación para dinamizar procesos escolares y generar alternativas metodológicas para construir una escuela cercana a la configuración de un espíritu científico. En esta línea, la investigación es entendida como la herramienta básica de producción de conocimiento, y es el soporte para introducir a niñas, niños y jóvenes en el camino del pensamiento crítico, que les facilita los aprendizajes que corresponden a su grupo de edad.

Variadas propuestas metodológicas surgen provenientes de diversas latitudes. Su preocupación no es solo la investigación, sino también el acto de enseñar y aprender, y, por tanto, el perfil de maestro requerido y su papel frente al conocimiento. Asi mismo, las gestiones requeridas de este profesional dan forma a una institucionalidad diferente, coherente con la apuesta metodológica para el desarrollo de la vida escolar.

\section{Replanteamientos de la acción y la práctica}

De igual manera, surgen infinidad de concepciones sobre la acción y la práctica que constituirán escenarios propios de in- vestigación, dando forma a múltiples ideas derivadas de ellas. Esta diferencia puede verse cuando se conciben diferentes tipos de acción, lo cual significa su ampliación y, por lo tanto, salir de la mirada pragmática; tal como lo hace Ricardo Lucio $^{20}$, quien afirma la existencia de muchos tipos de acción que pueden solucionar problemas y ser un elemento con y a partir del cual se construye el conocimiento. En su reflexión, Lucio identifica cinco tipos de experiencias que, retomadas para los procesos de acción, serían:

a. La acción real concreta, mediante la cual se transforma físicamente el mundo.

b. La acción representada, mediante la cual se reconstruyen mentalmente, o se identifican en un contexto, esos procesos.

c. La acción abstracta, que no maneja objetos sino conceptos abstractos, los cuales, a la vez, son resultado de acciones anteriores, como cuando saco la raíz cuadrada de una cantidad.

d. Acción sobre las cosas del mundo o sobre las personas, que puede transformarse en una acción social o interacción.

e. Acción mental o reconstrucción de las acciones de otros, para la cual es necesario valerse de representaciones cifradas, tales como el texto o el relato, como sucede en la representación de los procesos históricos o en cierto tipo de narrativas.

Esta interpretación de la acción permite reconocer a la práctica como fuente de saber y conocimiento, lo que ha llevado, durante los últimos tiempos, a perfeccionar las metodologías que hacen posible el paso hacia una enunciación categorial rigurosa y permiten encontrar la reflexión crítica en la acción, haciendo evidente la riqueza de los procesos que van más allá de los resultados.

La consolidación de las diferentes propuestas de investigación en estas líneas (acción y práctica), ha llevado, no solo a encontrar sus productos conceptuales, visibles en libros, videos y cartillas, sino a una perspectiva metodológica plural, en el sentido de que han surgido diferentes enfoques, mostrando un campo fértil de debate en la riqueza epistemológica subyacente a esta diversi-

20 Lucio, R. (1994). La construcción del saber y del saber hacer en pedagogía y Educación Popular. Revista Aportes, No. 41. Bogotá: Dimensión Educativa. 
dad conceptual. Estos elementos han situado a los maestros y maestras en la posición de investigar sus prácticas, lo cual les ha implicado reelaborar las metodologías propias de las ciencias en sus distintas concepciones: experimental, etnográfica, de acción participativa, teoría fundada, entre otras.

De igual manera, se han abierto búsquedas para constituir procesos investigativos propios de la especificidad del maestro y la maestra. Una de ellas es la sistematización, que comienza a ser entendida como una forma de investigar las prácticas, o de producir saber y conocimiento, desde la manera en que se lleva a cabo el ejercicio social de las profesiones, haciendo visibles las capacidades y habilidades desarrolladas en esos procesos.

Estas búsquedas, que vienen de diferentes latitudes y han configurado campos específicos de investigación, son acompañadas de una reflexión que comienza a replantear (en el mundo del norte) la mirada única de la ciencia basada en el positivismo ${ }^{21}$; esta reflexión encuentra una rica veta en los estudios que se comienzan a producir en la física cuántica, la química de gases, la biología molecular y muchos otros lugares clásicos del conocimiento, hecho que es de utilidad práctica para las necesidades del mercado. Preguntarse por esos nuevos lugares significa replantear muchos de los asuntos que se habían constituido como variables permanentes en los procesos de investigación y educación y que parecían muy definidos. Entre ellos tendríamos:

- Re-conceptualizar el saber y el conocimiento.

- Deconstruir, una manera de entender el conocimiento científico.

- Mirada crítica latinoamericana.

21 El paradigma científico postivista tiene su origen en el mundo griego, en donde se tenía la certeza de que los teoremas matemáticos eran el reflejo exacto del mundo real, por lo tanto, eran la expresión de la verdad. De igual manera, se reproduce en la lógica aristotélica, cuyos conceptos fundamentales son expresión de la realidad. La edad moderna le da las bases físicas a través del determinismo presente en las leyes de la física mecánica. Descartes entrega sus bases filosóficas cuando establece el dualismo mente-materia. Ello hace que el mundo material pueda ser descrito objetivamente sin relación, ni referencia, al objeto observador. Por su parte, Galileo, encuentra el método para lograr que esa realidad, que ya está hecha, acabada, y por lo tanto es objetiva, pueda ser conocida a través de nuestro aparato cognitivo (unidad de percepción pura kantiana) que, como un espejo, la refleja en él. Por ello, la verdad era la fidelidad de nuestra imagen interior a la realidad que representa. Todos estos principios definen a la ciencia a partir de: La objetividad del conocimiento; el determinismo de los fenómenos; la experiencia sensible; la cuantificación aleatoria de las medidas; la lógica formal y la verificación empírica.
- El conocimiento como poder.

- La pregunta por el todo y las partes.

- Otras formas de poder.

\section{Reconceptualizando saber y conocimiento}

El replanteamiento de las ideas de saber y conocimiento cuestiona esa mirada de una comprensión epistemológicamente única, que desprecia otras formas de comprender, y abre la posibilidad de reconocer la manera en que existen otras formas de $\operatorname{saber}^{22}$. Esta discusión logra una primera re-conceptualización con los planteamientos de Foucault, para quien: “[...] el saber no es la ciencia, y es inseparable de tal y tal umbral en el que está incluido: incluso los valores de lo imaginario, incluso la experiencia perceptiva, incluso las ideas de la época o los elementos de la opinión común ${ }^{23}$.

El saber es la unidad de estrato que se distribuye en los diferentes umbrales, mientras que el estrato solo existe como acumulación de esos umbrales bajo diversas orientaciones; la ciencia solo es una de ellas. Solo existen prácticas o posibilidades constitutivas del saber: prácticas discursivas de enunciados, prácticas no discursivas de visibilidades; las relaciones entre ciencia y literatura, o entre lo imaginario y lo científico, o lo sabido y lo vivido, nunca han constituido un problema, puesto que la "concepción del saber impregnaba y movilizaba todos los umbrales" $" 24$.

\section{Deconstruir: una manera de entender el conocimiento científico}

Toda esta discusión, desarrollada a lo largo del siglo XX y profundizada a comienzos del XXI, abre un camino para reconocer el papel de ese conocimiento hegemónico en la actualidad. Retomando las perspectivas de Comte y Durkheim, es posible encontrar que el estudio implica reconocer distintas formas críticas, desde las que provienen de la tradición latinoamericana, que permiten ver que el "encuentro de dos mundos" configuró unas formas de conocer que incluyeron también el "encuentro" de las experiencias del colonialismo y la coloniali-

\footnotetext{
22 Unesco. (1986). Declaración de Venecia. Comunicado final del coloquio. Venecia: Unesco. Obtenido desde http://unesdoc.unesco.org/ images/0006/000685/068502sb.pdf

23 Se recomienda consultar Revista Ciudad y Educación. No. 22 y 23.

24 Deleuze, Guilles. (1987). Foucault. Barcelona: Paidós, p.79
} 
dad con las necesidades del capitalismo ${ }^{25}$, hasta las que retoman la tradición euroamericana y la transfieren a la discusión de nuestro contexto.

\section{Mirada crítica latinoamericana}

La mirada crítica latinoamericana señala que la esfera del conocimiento constituyó, bajo una mirada eurocentrista, un nuevo universo de relaciones intersubjetivas de dominación, cuyo eje fue Holanda, con Descartes y Spinoza e Inglaterra con Locke y Newton. Este enfoque elaboró y formalizó un modo de producir conocimientos que daba cuenta de las necesidades cognitivas del capitalismo; además, ofreció un modo particular de producir el conocimiento, desde lo racional, la medición, lo cuantificable y la objetivación como forma de salir de la subjetividad y construir lo objetivo en la externalidad. Estas características dadas a esa forma de lo cognoscible por el proyecto de poder, es asumida universalmente por todos los educados bajo su hegemonía ${ }^{26}$.

Desde esta perspectiva, la educación se convierte en uno de los elementos centrales para "naturalizar" la experiencia de las personas bajo el patrón de poder cognitivo fundado en ese conocimiento específico. Por ello, se plantea la necesidad de discutir esa episteme del conocimiento centrado en elementos de verdad y universalidad, cuestionando la manera como autoconstituye su legitimidad a partir de formas y procesos históricos del inicio de la modernidad europea; además, se pregunta cómo esta forma particular de un conocimiento local se hace universal y cuáles son los elementos que hicieron posible esta situación ${ }^{27}$.

\section{El conocimiento como poder}

De igual manera, la mirada latinoamericana cuestiona cómo se da el movimiento que determina que el pensamiento eurocéntrico es la única forma de producir la verdad y saber sobre lo hu-

25 Quijano, Aníbal. (1992). Raza, etnia, nación. Cuestiones abiertas en José Carlos Mariátegui y Europa. Lima: Amauta. 1992. También es posible ver Mariátegui, J. C. (1963). Ensayos de interpretación de la realidad peruana. Lima: Amauta.

26 Lander, E. (s.f.). Ciencias sociales: saberes coloniales y eurocéntricos. Obtenido desde http://www.oei.es/ salactsi/mato2.htm

27 Es interesante ver cómo los pensadores críticos de los grupos aborígenes norteamericanos han sugerido una corriente semejante que ha trabajado las racionalidades diferentes o alternativas; en pedagogía crítica esta perspectiva ha tomado el nombre de post-formalismo y su representante más reconocido es Joe Kincheloe.

Educación y Ciudad No 29 Julio - Diciembre de 2015 ISSN 0123-0425 - PP 16 - 38 mano, y la naturaleza que lo lleva a separar las ciencias naturales de lo humano. Desde esta pregunta se llega a la idea de que es necesario relacionar este pensamiento a los escenarios de poder y a la forma en que éstos se constituyen en el saber formando otro escenario de poder que debe ser analizado.

Todo ello abre una búsqueda, una conversación sobre la manera en que la idea de totalidad deja por fuera muchos aspectos de la experiencia histórico social o los acoge parcialmente de acuerdo a los intereses implicados en el saber y el conocimiento. Habría que trabajar en otras cosmovisiones, en lógicas múltiples y en tratar los lenguajes de la segregación presentes en otros procesos culturales, pues también hacen visible la episteme del poder.

\section{La pregunta por el todo y las partes}

La perspectiva latinoamericana también abre interrogantes sobre la relación entre el todo y las partes en cualquier organización humana, biológica o social, cuestiona a su vez la forma en que esta relación opera en otras dimensiones del conocimiento. Al tiempo, reflexiona sobre si esta correspondencia se da en una misma lógica de existencia o si, por el contrario, cada uno de uno de sus componentes tiene especificidades que abren caminos para dar un lugar a la singularidad. Por esa vía se plantea lo que significaría ver totalidades históricamente heterogéneas, cuyas relaciones son discontinuas, inconsistentes, conflictivas, asistemáticas, que dieran un conocimiento sobre basado en otras bases epistémicas.

Si se reconocen estas características, es evidente que hay una diferencia entre la perspectiva eurocéntrica y la latinoamericana en cuanto a la relación con la totalidad, ya que el funcionamiento planteado por la segunda no se da a través de modelos y, en ese sentido, da lugar a los saberes variables, locales, ligados al contexto, a la particularidad con identidad de territorio.

\section{Otras formas de poder}

La visión más crítica de la perspectiva latinoamericana hace énfasis en la necesidad de reconocer que se ha dado un doble condicionamiento que hace que las formas de saber no sean reconocidas como conocimiento universal: en el conocimiento se da un doble control, no solo de tipo eurocéntrico, sino androcéntrico y patriarcal: WASP Blanco, euroamericano (anglosajón), protestante, masculino y académico. Esta manera de 
control tiene como característica principal el hecho de que invisibiliza a otras epistemes y a lo diferente.

\section{Construir un estatus propio de la práctica}

Con los desarrollos planteados anteriormente, pero también con la emergencia de profesiones que fueron encontrando durante el siglo XX procesos de intervención que comenzaron a ser entendidos como sistemas de mediación ${ }^{28}$, se ha ido encontrando un cuestionamiento al dominio único de producción de conocimientos de la ciencia moderna. En ese sentido, comienza una revaloración de las formas de conocer y de los sujetos del conocimiento, que incluye los saberes, los sujetos de la acción y los conocimientos locales, mostrando que la intervención, vista como mediación, es un espacio de acción y de relaciones, un campo de saber susceptible de organizarse desde una perspectiva que no parta únicamente de lo racional y lo cognitivo, lo cual implica captar una serie de tramas complejas que se mueven en su interior y dan unidad y sentido a su práctica.

Esta discusión ha permitido hacer la pregunta sobre cuál es el lugar de la práctica; lo que llevó a la necesidad de construir un estatus en ella que haga posible que la praxis, los procesos de intervención social y los conocimientos locales y populares sean organizados como saberes que empoderan a quienes realizan la acción. Esto, gracias a que los coloca en la doble relación del saber hacer y el saber qué se hace, desde dónde se hace y para qué se hace, en el sentido planteado por João Francisco De Souza $^{29}$ (hacer, sentir, pensar). Así, se reconoce que en estos tres procesos (prácticas locales y populares, intervención y saberes locales-populares) hay saberes que existen, se crean, se reproducen socialmente y operan como reguladores en los ámbitos de acción humana, y tienen referentes éticos y valorativos que los colocan en esos contextos de acción.

Por eso se ha dado, sobre todo a finales de los años $80 \mathrm{y}$ comienzos de los 90, un intento por desentrañar estos saberes, lo cual significa reconocerlos como epistemológicamente vivos, por lo que requieren de un diálogo con el llamado conocimiento universal, para construir argumentos que permitan enfrentar el

28 Martín-Barbero, J. (1987). De los medios a las mediaciones. Barcelona: Editorial Gustavo Gili.

29 De Souza, J. F. (2001). Atualidade de Paulo Freire. Contribuição ao debate sobre a educação na diversidade cultural. Recife: Edições Bagaço. paradigma positivista y su fatídico determinismo de que solo la ciencia produce conocimiento, mientras que la práctica solo lo aplica. Es así como diferentes autores afirman que hay una teoría subyacente a la acción, ésta solo puede ser vista si se rompe el modelo del conocimiento en su versión académica, y ello significa ubicarse epistemológicamente en otro lugar ${ }^{30}$.

\section{Los flujos de relación}

Comienza a aparecer una trama propia de este tipo de conocimiento, pues se demuestra que los procesos de acción, saber y conocimiento no son niveles separados de la condición humana, ni de la realidad con la cual nos relacionamos; son vínculos presentes en las prácticas y en las relaciones sociales. El punto en este momento es salir de la idea de que saber y conocimiento son elementos diferentes y enfrentados, como si fueran estancos separados o niveles sin ninguna interrelación; para hacerlo es necesario establecer un campo que permita deconstruir las diferencias, entender de otra manera el conocimiento científico y ver de qué modo el sistema de relaciones nos lleva a entenderlo desde otro lugar, desde un espacio en el que el vínculo entre lo científico y el saber se constituya a través de flujos de relación, dando lugar a un estatus de la práctica que se aplica en una realidad no fragmentada o desarticulada.

\section{Interculturalidad}

De igual manera, emerge con mucha fuerza una dimensión intercultural construida por actores humanos que están en uso de las herramientas culturales en lugares precisos, con contextos específicos y en una culturalidad situada. Una trama intersubjetiva en la cual las prácticas y los sujetos producen una red en relaciones sociales, en ella las diferencias tienen que ser reconocidas y hacerse visibles a través de los ejercicios de saber de esos actores desde sus particularidades; al ser reconocidas se evita la negación.

El silenciamiento, la invisibilización gestada por las relaciones asimétricas, se hace visible en el ejercicio de socialización de la práctica. Por ello es necesario reconocer cómo aproximarse a estos saberes que están en la trama de la cultura, también se re-

30 Bordieux, P. (1994). Raisons practiques. Sur la théorie de l'action. Paris : Seuil. También, Barbier, Jean-Marie. (1996). Savoirs théoriques et savoirs d'action. París : Presses Universitaires de France. 
quiere de un marco de atención diferencial que facilitará darles su especificidad. Este es el ejercicio de negociación cultural y de diálogo de saberes propuesto por la Educación Popular ${ }^{31}$.

\section{Lógicas del saber de la acción}

Considerando lo dicho hasta el momento, es posible ver que la práctica cambia su función, convirtiéndose, no solo en un espacio en el cual los saberes están en la acción, sino en un escenario de creación de saberes. Su definición ya no es la de un lugar en el que se hacen adaptaciones, adecuaciones o aplicaciones del conocimiento aprendido, pues se sabe que en muchas ocasiones esos saberes de acción son de origen científico y son readecuados, reorganizados, reformulados y transformados por la misma práctica.

Estos saberes de práctica se gestan y se desarrollan desde una lógica de acción, son vistos como la inclinación y la potencia de los actores, quienes buscan el saber que fundamenta aquello que hacen; esto significa que no solo deben ubicar los criterios desde donde hacen su trabajo o explican su descripción en la esfera de la razón, sino que deben tener la capacidad de dar cuenta de ese saber que construye las relaciones de que aquello que hace, dándole un contenido en la esfera de la teoría.

\section{Producción del sujeto de práctica}

Este saber de acción, que es territorializado y puede llegar a un conocimiento derivado de la práctica, recorre un camino reflexivo centrado en quien practica y en la práctica misma; ello exige plantearse la relación de esa práctica con el practicante, con otros sujetos, con el medio en donde se realiza la acción, con los tipos de abstracciones que dan cuenta de la fundamentación y con los resultados aprendidos con la práctica que, al ser formalizados, toman el camino de la experiencia y hacen visibles actitudes y comportamientos, haciendo emerger lo que algunos autores han denominado los sistemas auto-observantes, que dan lugar a la investigación de segundo orden ${ }^{32}$.

Este nudo de relaciones es como un entramado social que necesita ser teorizado, formalizado y, si es necesario, puesto en relación con el conocimiento preexistente, el cual permite dar

\footnotetext{
31 Mejía, M. R. (2012). Educaciones y pedagogías críticas desde el sur. Cartografías de la Educación Popular. Bogotá: Editorial Magisterio.

32 Ibáñez, L. (1994) El retorno del sujeto. Santiago de Chile: Editorial Amerindia.
}

Educación y Ciudad No 29 Julio - Diciembre de 2015 ISSN 0123-0425 - PP 16 - 38 cuenta de la manera como la práctica adquiere también un estatus de saber relacionado con el conocimiento disciplinario y su historia, para estar en capacidad de establecer un proceso en el cual el conocimiento que se genera desde la práctica rompe el umbral de esos acumulados disciplinarios.

Dar cuenta de es un ejercicio que requiere de un diálogo con lo constituido. Desde esta perspectiva será posible hablar de una práctica que tiene una dinámica propia para relacionarse con el saber que la constituye y con el conocimiento que la fundamenta, en el sentido de que el saber pertenece a un campo de práctica y tiene una frontera de relación con el conocimiento que debe ser auscultada y reflexionada para hacerlo experiencia y dar cuenta de él, no en forma separada, sino desde una nueva unidad que se autoconstituye. Por ello, la sistematización es una práctica que funda ese acercamiento.

\section{Características de la teoría que surge de la práctica}

Es necesario reconocer que en los procesos de intervención social y en los saberes locales y populares existen saberes preexistentes a la práctica, que también se crean desde la organización y la intervención que se realiza en ella. Así, es posible ver el flujo de relaciones que auto-constituyen la práctica: pues la define desde su vínculo con la teoría, en el sentido de que se constituye como un nudo de relaciones que requieren ser conceptualizadas. Por eso, en esa doble instancia: acción-práctica-nudo, está el entramado que permite descubrir la naturaleza local y contextualizada desde la que opera la práctica.

\section{Diferentes formas de saber}

Con todo este movimiento surgen diferentes formas de saber, conocimiento y sabiduría. Por un lado, la acumulada en la práctica como forma de un saber presente y fruto de toda una tradición; por otro, en cuanto práctica, como forma de intervención que requiere de un ejercicio reflexivo para dar cuenta de lo que hace y de sus resultados. También aparece un entramado intersubjetivo de las emociones y afectos que cruzan los procesos humanos y que están presentes como elementos implícitos en las prácticas. De igual manera, están presentes los sentidos y las apuestas políticas y éticas realizadas por los sujetos en estos contextos. 
Estas no son formas menores del conocimiento científico, ya que en muchas ocasiones lo conciben. Por ello, un buen ejercicio para encontrarlo implica trabajar alrededor de cómo se da la relación entre saberes y conocimientos en la práctica, sea desde la diferenciación, la negación o de asumirlos como parte del propio fundamento, ya que en cualquier sentido abren un camino, no solo de autoafirmación, sino de reconocer las relaciones con ese otro conocimiento.

\section{Epistemológicamente vivos}

Una de las características que validan a la teoría que surge de la práctica es que los saberes son epistemológicamente vivos, es decir que son construidos por los grupos que hacen la intervención y cuentan con objetivos mediados por sistemas de auto-constitución en la interacción de los actores con el mundo. En muchas ocasiones, los saberes dependen de la experiencia de quien adelanta la práctica y esto los define como algo complejo, específico y en ocasiones innovador, a pesar de que en algunos casos sea un evento exento de reflexión. Este es el punto fundamental, porque no es la reflexión que viene de fuera la que los constituye, sino la capacidad de dinamizar los potenciales de los actores en su interior ${ }^{33}$; desde allí será posible dar cuenta de los sentidos, de las finalidades que están presentes en la acción misma y dar otra forma a lo teórico, auto-constituyendo estos sistemas desde un proceso de conocimiento y reflexión.

\section{Social y culturalmente diferentes}

Lo social y culturalmente diferente es lo que trabaja desde formas de conocer basadas en saberes interculturales; para José Luis Grosso, el gran problema del sistema eurocéntrico es que en él se gesta una "sociedad del des-conocimiento" 34 que no reconoce las diferencias y homogeniza, tanto en su interior, como en el exterior, generando saberes subalternos a los que nuevamente no se les permite tener su propia voz y terminan

33 Este sería el sentido más profundo para recuperar la integralidad, la unidad del trabajo inmaterial y el trabajo material (mano-mente) desde la idea de biopoder. Para ampliar este tema, se recomienda ver: Mejía Marco Raúl (2009-Agosto). Las pedagogías de la resistencia. Le monde diplomatique. Año VIII.

34 Grosso, J. L. (2005). Políticas de la diferencia. Interculturalidad y conocimiento. Ponencia presentada en el Seminario de FLAPE. Sin publicar. aspirando a ser integrados a esa racionalidad "mayor" del conocimiento académico.

Así, reconocer la interculturalidad significa que toda acción de intervención se da desde la reflexión, para desde allí encontrar la teoría que se busca desarrollar; en este sentido, aparecen cuatro componentes que están unidos en esa red de la unidad de la práctica. El primero, es que la práctica se da en situaciones en conflicto que requieren de una negociación cultural para dar cuenta de la forma en que se integra su saber. El segundo, es que implica reconocer las voces polifónicas; por ello, los textos no tienen la unidad clásica de lo racional, permitiendo la aparición de las voces de muchos sujetos. Esto da espacio a un tercer componente, el del contexto, que opera bajo las determinaciones de la cultura y exige un diálogo permanente de saberes para hacer visible la teoría desde los lugares en los que se gesta, posibilitando un conocimiento real desde la cultura. El cuarto es la subjetividad, que da lugar a los sistemas auto-observantes en el proceso y no es externa al producto, sino algo interno, constituido y constituyente.

\section{Otras formas de teorizar}

Estamos buscando, desde la práctica, un sistema de teorización que permita no "naturalizar" la experiencia de las personas en un solo patrón; esto significa renovar los fundamentos del conocimiento histórico-social y elaborar una racionalidad que, sin depender de la eurocéntrica, sea capaz de dar cuenta de estos procesos y de dialogar con los pensamientos ya establecidos. Esto significa dar cuenta de la historia conceptual de la práctica, el camino que ha tomado hasta convertirse en experiencia, lo cual implica introducir una dimensión de reflexión interna; es así como se descubre la riqueza epistemológica de los saberes en la acción.

Esto obliga a iniciar una búsqueda de metodologías que permitan el surgimiento socialización de los trabajos realizados sobre el conocimiento desde la práctica; de igual manera, implica dar el paso a una enunciación conceptual que construya un rigor propio capaz de facilitar el tránsito entre el saber común, desplegado en las prácticas, y el otro saber, constituido, no desde el exterior, sino a partir de ellas. Además, significa encontrar la capacidad reflexiva de la acción, y del saber que se produce, ligada al conocimiento y a la teoría, entendiéndolos como aliados, no como un antónimo en el cual la organización del saber se asume desde la forma del poder de otros. La idea es que el ejercicio de 
poder-saber dispute los espacios de un saber-conocimiento, el cual también construye otros referentes éticos y políticos.

Es en este camino donde la práctica emerge convertida en experiencia, validada por ella y por su capacidad de demostrar que está constituida por diferentes tipos de saberes y conocimientos; así forja un campo de investigación sobre los tipos de conocimientos que constituyen a los saberes de acción, mientras, al tiempo hace evidente la manera como se generan las dinámicas de reflexividad, sus mecanismos específicos de desarrollo y la forma como se relacionan con las dinámicas sociales que originan estos nuevos saberes. Ese es el campo abierto para pasar de la práctica a la teoría y, en ese sentido, es un cambio de la pregunta por el lugar de la práctica y del conocimiento.

Antes nos habíamos preguntado cómo son las cosas, cómo es el conocimiento verdadero, ahora nos preguntamos cómo son los procesos que dan lugar a las cosas; esto significa asumir ese conflicto de la constitución de los procesos para pasar a un mundo en el cual, reconociendo nuestra acción y reconociéndonos como seres que actuamos, reconocemos nuestra capacidad de producción de saber. En ese sentido, es la potencia del conflicto, entre el trabajo manual y el trabajo intelectual, la que nos lleva a recuperar los saberes que tienen potencia para convertirse en conocimiento y hacer el camino de la teoría.

En ese ejercicio se auto-genera el empoderamiento que hace posible entender la sistematización como una forma de investigación que ha revalorizado los saberes de la práctica, el mismo que constituye una propuesta investigativa para hacerlos emerger como saberes que no solo dan cuenta de las prácticas, sino que las transforman y las convierten en procesos de empoderamiento de actores, organizaciones y grupos humanos, que se reconocen como productores de saber desde y para la acción ${ }^{35}$.

\section{La investigación en el mundo del/la maestra(o)}

Toda la discusión que se da hoy sobre la ciencia, la emergencia del "modo 2 de la ciencia" (llamado también "tercera cultura"), la ciencia no lineal y los replanteamientos y debates sobre los métodos y los procedimientos, abre una gran puerta para repensar el problema de la investigación en la especifici-

35 El desarrollo de cómo la sistematización rompe esos dualismos, desborda las pretensiones de este texto. Por ello solo los dejamos enunciados. Para ampliar y ver mi propuesta metodológica de sistematización, remito a mi texto La sistematización empodera y produce saber y conocimiento. Bogotá. Ediciones Desde Abajo. 2008. dad del conocimiento y, por lo tanto, en el saber pedagógico; esta entrada nos presenta a un maestro y una maestra que, al ser practicantes de unos conocimientos establecidos en los contextos y en tensión entre lo universal y lo "pluriversal", exigen una construcción de metodologías y reflexiones que, mientras reconocen su especificidad y la riqueza de sus prácticas, los conviertan en productores y productoras de saber y conocimiento.

Esto significa una ruptura con la mirada clásica y la manera de entender cómo se ha formado este oficio, pues se apela a investigaciones desarrolladas desde otros ámbitos, en el marco de la separación entre ciencias naturales y ciencias sociales que ha generando una especie de fragmentación de su práctica y sus conocimientos. Establecer esta unidad implica una reflexión de fondo sobre la identidad del maestro y la maestra, a la luz de estos cambios epistemológicos y metodológicos, lo cual abre un espacio para construir metodologías diversas y caminos que, recuperando la práctica y la acción, hagan real a un docente que da forma a su integralidad como ser humano, no solo desde el desarrollo de procesos prácticos, sino desde su papel como forjador de la cultura y de nuevas realidades.

\section{Un saber práctico que busca conceptualización}

El quehacer de maestras y maestros nos coloca frente a un saber práctico, en el cual deben reconocer las tensiones y el conflicto de entrar en la lógica del descubrimiento y salir de la de la repetición y la memorización. Esto lleva al maestro o maestra a ver su práctica y aclarar sus propios procesos; de igual manera, le lleva a tener una comprensión de los contextos desde los cuales actúa. Entonces, se establece en la práctica pedagógica toda la mirada de la investigación de segundo orden y de esa "tercera cultura" de la ciencia, en la cual el sujeto está implicado en aquello que observa. Esto va a determinar una particular manera de establecer la actividad investigativa sobre su práctica.

Nos encontramos con el hecho de que el propio actor se enfrenta a la comprensión de su práctica como un hecho complejo, así, no solo tiene que interpretarla, sino que también debe entender los contextos en los cuales se produce. Encuentra que no se trata de un saber de repetición, sino que su práctica se enriquece cuando la convierte en objeto de observación, lo cual modifica su quehacer. La práctica pedagógica queda sometida a rigurosas condiciones de observación, y el propio sujeto que la realiza se ve obligado a construir unas características específicas que hacen de su conocimiento y saber un proceso social 
pedagógico, en el cual no solo se repite, sino que se reelabora, se enriquece y reconstruye.

La mirada sobre el quehacer del maestro destaca la especificidad de la naturaleza del saber pedagógico, porque lo ubica como un saber propio de un sujeto que no solo opera con las condiciones de la ciencia en el sentido más tradicional, sino que lo hace desde un arte específico inherente al ejercicio práctico de su profesión. El maestro o la maestra deben estar en condiciones de percibir situaciones siempre nuevas y problemáticas -las cuales debe convertir intuitivamente en preguntas y responderlas- que se presentan su profesión; esto le significa no solo percibirlas, sino construir prácticas nuevas para dar respuestas apropiadas a las situaciones que se le presentan ${ }^{36}$.

Esas situaciones cotidianas de la pedagogía no encuentran respuestas en el saber acumulado o en paradigmas universales, son nuevas en su singularidad y no pueden ser resueltas por ningún libro o teoría; así, el saber del maestro se encuentra en el punto intermedio entre los aspectos disciplinarios que corresponden a la historia de su campo, y un quehacer práctico en donde el docente se ve obligado a desplegar su condición humana creativa para resolver la situación, generando una forma de hacer y conocer que tiene elementos del "conocimiento científico", pero que rompe el molde en el que éste ha sido constituido.

Por eso podríamos afirmar que la pedagogía tiene una cierta sistematicidad, lo que la une a ese saber universal, pero, al tiempo, tiene un aspecto de diferencia que la une a saberes prácticos (arte de). El maestro debe estar atento a esta tensión, pues cuando el llamado "saber universal" se recrea en situaciones cotidianas, no se aplica como principio universal; allí emerge un maestro que, cuando está atento, encuentra que para que su práctica pueda ser trabajada con criterios de calidad, de innovación y de producción de saber y conocimiento, debe proponerle y crearle una actitud investigativa.

Esta actitud investigativa ya está en la práctica del maestro innovador; cuando el docente decide pensar en cómo ha resuelto una situación problemática, encuentra que ha seguido pautas de un proceso investigativo: se hace preguntas sobre el proceso; se da cuenta de que con esas preguntas organiza un conjunto de propuestas sobre su práctica, las cuales reconoce como propias y específicas de su quehacer; las contrasta en su dimensión práctica; plantea caminos de solución; se propone saber más sobre

36 Mejía, Marco Raúl. (2007). El maestro y la maestra investigadora: fundamento de las geopedagogías. Bogotá. Sin publicar. las situaciones problemáticas, convirtiendo su quehacer en un laboratorio vivo; y cuando se da cuenta de que debe aplicar procedimientos tomados de diferentes métodos y enfoques para dar respuesta a esos problemas, reconoce un quehacer investigativo propio de su práctica; cuando esto ha sucedido, emerge el maestro(a) investigador(a).

En este momento, el docente se encuentra con los discursos propios de los paradigmas de la educación y, mientras discute con ellos, reelabora su práctica, retoma la historia, la contrasta y la reelabora. Allí construye innovación, haciendo de su práctica un proceso investigativo, allí produce su vida con sentido creador. Sistematizar su práctica, reflexionarla y escribirla no solo le hace diferente, sino que le permite recuperar los sentidos de novedad y de acontecimiento que la repetición había sacado de su vida, pues todo el proceso le obliga a dar cuenta de los fundamentos y principios conceptuales de su proceso, generando un saber pedagógico propio que lo convierte en productor de saber.

\section{Producción de saber: un entendimiento de la práctica y del maestro}

Plantear la relación de la práctica con el saber y el conocimiento, implica una revisión de la mirada clásica que fragmenta la relación entre teoría y práctica desde dualismos (materia-espíritu, natural-sobrenatural, naturaleza-humano) que, a su vez, separan las relaciones entre sujeto y objeto, planteando al conocimiento como algo externo al sujeto, convirtiéndolo en un hecho objetivo, verdadero y fijo; debido a que el saber se da desde una búsqueda de elementos semejantes a lo verdadero, se construye una forma de la ciencia que la obliga a clasificar, generalizar, ordenar y definir, diluyendo lo diferente. Por eso, esta visión afirma que el conocimiento es un hecho posterior a toda práctica, y que ésta es una forma incipiente y menor de él.

En este sentido, el saber como resultado de una práctica es anterior a la disciplina, a la ciencia y al conocimiento generado. Como el saber es práctico, es desde de allí que se va hacia las otras formas de conocer, por eso se entiende que el sujeto de saber es despojado del mismo debido al empobrecimiento histórico al que se vio sometido el pensamiento sobre la práctica. Aquí el llamado es a reconocer la emergencia de un saber propio en los practicantes. Como lo reconocen las y los maestros expedicionarios de Bogotá: 
En los anfitriones, los expedicionarios encontramos maestros que saben que hay mucho por hacer y lo vienen haciendo sin importar los áridos caminos que han recorrido y que tengan que recorrer. Maestros que creen en sí mismos, en su formación entre pares; maestros que buscan a diario una identidad digna de su profesión, que propician acercamientos con su comunidad educativa; maestras que creen y trabajan por una nueva etapa de la historia de la educación y la pedagogía en Colombia, pues están convencidas de que no es posible pensar la escuela en abstracto, sin un referente territorial, cultural, ético, de género, y por supuesto, social $^{37}$.

Así, podemos afirmar que el sujeto de práctica se propone a sí mismo como objeto de un saber; estamos frente a un observador que se auto-observa y se ve retado a pensar lo que hace; allí reconoce que debe preguntar no solo por quién es, sino por qué hace, por el cómo y dónde lo hace. Al ver sus prácticas y tener que pensarlas y analizarlas, nace otro sujeto que está más allá del practicante activista; al mirarse a sí mismo reconoce que no solo hace lo que se le ordena, también realiza cosas diferentes de las que debe hacer (enseñar según las pautas determinadas por el conocimiento o el poder) y, por ello, se ve en la necesidad de pensarse de otro modo, porque habla de su quehacer y de la novedad de cómo lo hace, no de lo que repite.

Cuando el docente se analiza desde su práctica se ve obligado a dar cuenta de cómo ocurrió todo, de cómo se planeó; es decir, cuenta cómo se objetivó la enseñanza en su proceso y determinó su práctica de enseñar. Salir de una práctica que reduce su vida a un oficio repetitivo, significa que debe reconocer cómo es su práctica y entender cómo modifica su mundo concreto, así va recreando su quehacer. Como dicen los maestros del Valle: "Encontramos maestros que en sus prácticas rompen con aquellos imaginarios que ven la escuela como un simple aparato de transmisión de información" $"$.

La práctica se convierte, no solo en una acción mecánica, sino en una dinámica creativa que es visible en los modos de actuación y pensamiento. Por ello es posible afirmar que el maestro no es solo un sujeto de saber: lo produce, lo hace desde

37 Expedición Pedagógica Nacional. (2003). Caminantes y Caminos. Expedición Pedagógica en Bogotá. No. 4. Bogotá: Universidad Pedagógica, Fundación Restrepo Barco, p. 24.

38 Expedición Pedagógica Nacional. (2005). Recreando rutas y senderos pedagógicos en Valle, Cali y región norte del Cauca. No. 8. Bogotá: Universidad Pedagógica Nacional - Universidad del Valle, p. 26. su práctica; sino que también es un sujeto de conocimiento, pues su relación con la teoría se da en el acumulado disciplinario de ese saber.

El maestro es un sujeto de conocimientos cuando enseña desde principios coherentes con los planes, programas y teorías prefijadas desde métodos, paradigmas, modelos, currículos, calidades y evaluaciones; también es un sujeto de práctica determinado por su hacer-saber desde sus condiciones específicas de existencia, contexto, historia personal y vida, que le dan forma a ese saber. Sin embargo, hay una diferencia entre el maestro del conocimiento, que repite y lo hace de acuerdo con normas y procesos prefijados, sin novedad, como reiteración, y el de práctica.

El sujeto de enseñar (conocimiento) se convierte en sujeto de saber cuando no reduce la práctica de su oficio a la enseñanza, sino que la aborda desde una dimensión más holística al reconocerla como algo más amplio, hecho de relaciones y diversas formas de hacer y nombrar que lo llevan a introducir cambios y actividades. Cuando lo hace, reconoce que estas transformaciones son hechas por él y que así se constituye en un sujeto de enseñanza con un saber propio; identifica en su quehacer una práctica discursiva nueva y ella le permitirá producir un saber, umbral de nuevos conocimientos, que va más allá de lo formalizado en las disciplinas y en las ciencias pedagógicas establecidas.

Por eso el maestro de la Expedición Pedagógica Nacional se ha convertido en un sujeto de saber que reconoce su relación con la tradición y con la teoría de la educación, la pedagogía y la enseñanza. Sin embargo, cuando realiza su quehacer surge una nueva pedagogía que va más allá de enseñar y acontece en su vida cotidiana, en ella él produce un sentido de su vida y, al pensarla y comprenderla, también produce un saber sobre ella, lo cual le lleva a hacer un reconocimiento de lo cotidiano para comprender cuál es el sentido del saber y del poder en lo que hace. El saber está en su práctica, en la comunidad y en la institución; el conocimiento está en las facultades y los doctorados. Es en estos últimos donde construyen sus conocimientos desde un ejercicio en el que retoman sus prácticas para edificar lo que se transmite, solo que esta vez es un edificio renovado.

Este desencuentro, cuando es comprendido por los actores de Pedagogía, lleva a diferenciar entre lo que sería la historia de los métodos, los paradigmas y los enfoques, y todo el andamiaje técnico que hace posible la enseñanza y las historias de la práctica del maestro. Así, para poder producir ese saber el docente se asienta en la práctica pedagógica y en las múltiples relaciones 
constitutivas del poder. Ello le va a permitir construir, desde su práctica y en su historia, el nuevo saber pedagógico en marcha y en permanente reconstitución. Por eso se identifica como un creador-recreador de la pedagogía como práctica y, en este proceso, encuentra que se hace sujeto de saber.

En dicho espacio descubre que la gran novedad está en el poder que le otorga la capacidad de enunciar su práctica como un acontecimiento nuevo, mediante el cual se hacen visibles los saberes pedagógicos de su práctica: que construyen poderes. Entonces, el docente encuentra que el acontecimiento ha sido producido en su entorno y empodera su contexto, está en él, cuando se reconoce distinto a través de su práctica y de la manera como es capaz de hacer de ella un saber; por ejemplo, en la Escuela del Placer, de la costa Caribe:

La Expedición Pedagógica puso su mirada sobre este quehacer pedagógico cultural y descubrió una escuela que, casi de manera inconsciente, le hace su particular aporte a la paz por la vía del retorno a las raíces, de la reconstrucción de pertenencia y solidaridad, del cultivo de valores tradicionales y de la valoración del disfrute, la alegría y la fiesta como los motivos privilegiados para el encuentro, el respeto y el afecto ${ }^{39}$.

Su vida ya no solo tiene un sentido: enseñar, sino que en la novedad de su práctica se construye la capacidad de relacionarse con otros. Como lo afirma Maturana: encuentra que a través del lenguaje se hace una implosión con la que emergen los "biopoderes" en su vida y en sus capacidades, reconociendo la larga marcha por controlar su vida en su esfera subjetiva y, desde esa autonomía, construye comunidades "biopolíticas" desde la pedagogía. Se da cuenta de que puede aprender de su práctica y de los otros; una posibilidad de hacer de ésta una organización que le da sentido y potencia su quehacer.

El viaje como propuesta metodológica permite no solo ir geográficamente de un lado a otro, sino darle paso a lo diferente, a aquello que revisitado permite encontrar en el viajero los elementos que le muestran la construcción de mundos nuevos, y en ese observar encuentra cómo la diferencia le invita, en su práctica, a recorrer otros caminos y a visibilizar otras maneras de hacerlo. El viajero siempre tiene la certeza de otros mundos por descubrir, ya que al descubrir lo otro se manifiesta

39 Expedición Pedagógica Nacional. (2005). Rutas de vida, maestros, escuelas y pedagogía en el Caribe colombiano. No. 9. Bogotá: Universidad Pedagógica Nacional - Red pedagógica del Caribe, p. 65. la novedad de mi propia práctica, pensada a través de la práctica del otro, que me abre a nuevos mundos contenidos como experiencia. La cartografía se convierte en una u otra forma de narrar y dar cuenta de la manera como hablan las prácticas para convertirse en experiencias.

El maestro descubre así que su práctica, ubicada en los bordes del sistema educativo, también contiene el germen para reconocer el poder de su quehacer; descubre en ella resistencias y caminos alternativos con los cuales su quehacer se hace política en su propia vida, en la experiencia de nombrarlo con sus sentidos, significados, procesos y particularidades, enunciándolo y haciéndolo social.

\section{La experiencia, una visibilización de las geopedagogías $^{40}$}

La novedad de la práctica, del otro y la propia, ha permitido al maestro entender que sí puede hacer visible su vida, y la pedagogía como parte de ella, en sus prácticas; sin embargo, no son solo estos elementos los que se visibilizan, a ellos se suma la aparición de otro sujeto, uno renovado, que hace cosas más amplias y variadas que las pre-asignadas. El maestro encuentra que recrea un vivir permanentemente lleno de procesos y actividades, las

40 Nos referimos a geopedagogías entendiéndolas, no solo como territorio físico o geográfico, sino como múltiples territorios conceptuales, metodológicos, de interacción y de mediación de nuevos dispositivos que han emergido en estos tiempos, los cuales hacen necesario que el acto educativo sea reorganizado para estas nuevas realidades, exigiendo la construcción de nuevos procesos de mediación. Las principales geopedagogías son: a) Las contextuales, derivadas de los nuevos procesos en las realidades determinadas por los cambios epocales en su encuentro con la tradición; b) Las conceptuales, que se refieren a las nuevas demarcaciones construidas por los desarrollos teóricos del "modo dos de la ciencia", la ciencia no lineal, la tercera cultura de la ciencia y otras concepciones; c) Las generadas en las NTIC, que replantean, desde la existencia del lenguaje digital y la realidad virtual, las mediaciones anteriores y exigen unos planteamientos educativos y pedagógicos que vayan más allá de su uso instrumental como herramientas; d) Las territoriales, construidas por la emergencia del autorreconocimientos de un poder en el conocimiento generado en las latitudes norte-sur, lo cual implica miradas no eurocéntricas; e) De la ética, en las cuales, una vez replanteado el antropocentrismo como organizador del sentido de la acción humana, se recuperan otros entendimientos de la naturaleza y de la unidad planetaria y cósmica en el biocentrismo; f) Las de las desigualdades, trazadas por las formas de pobreza clásica, económica, social y política, en donde las nuevas realidades de la ciencia, el conocimiento y la tecnología fundan nuevas desigualdades. 
cuales debe hacer visibles; se ve obligado a enunciar lo vivido a través de un constructo mediante el cual explica aquello que hace, que existe en él y llena de sentido su vida.

Cuando la maestra y el maestro explican sus prácticas emerge la experiencia, ésta se explica desde una unidad propia: desde sus sentidos y apuestas (práctica-experiencia). Entonces surge una particularidad planteada por Maturana: "somos seres que existimos en el lenguaje". Ese paso de la práctica a la experiencia implica estar en capacidad de comprendernos a nosotros mismos, por ello, la experiencia corresponde a la comprensión del vivir y del convivir a través del hacer pedagógico. Si me quedara solo en la práctica especifica no necesitaría de explicaciones que den cuenta de mi quehacer. A pesar de que algunos consideren que esto no tiene importancia, es la palabra la que nos permitirá dar una explicación suficiente de nuestra práctica. Cuando aceptamos y reconocemos que ella es importante, cambia la práctica, queda indisolublemente ligada a la experiencia, iniciándonos como productores de saber.

Este momento es muy importante porque demuestra que el maestro no solo hace y observa lo que hace, sino que se auto-observa y produce un saber de su práctica. Por ello, el maestro y la maestra que participan de estos trabajos, y construyen desde esa observación de lo otro un proceso mediante el cual lee, discuten y replantean su práctica; aunque no lo niegan, no encuentran el sentido de su trabajo en la teoría o la objetividad, sino en una práctica que convertida en experiencia rehace las formas del conocimiento, transformando la enseñanza y su relación con el entorno, constituyendo lo político desde su práctica. Así, logran reconocer que:

El maestro y la maestra son unos seres sujetos de deseo que desarrollan su labor desde sus afectos, creando espacios alternativos, desde la misma escuela, donde le es posible compartir y crecer [...] lo que empuja a los maestros expedicionarios a elaborar sus rutas de superación en el amor y en el compromiso frente a su profesión. Se desencuaderna así lo normativo, al convertirse en algo más que simples impartidores de currículo, para ellos el programa es tan modelable como la plastilina, toma la forma que proponga la realidad del niño y cómo éstos se acomodan a la escuela ${ }^{41}$.

41 Expedición Pedagógica Nacional No. 1. (2001). Huellas y registros. Bogotá: Universidad Pedagógica Nacional, p. 120.

Educación y Ciudad No 29 Julio - DiciemBRe de 2015 ISSN 0123-0425 - PP 16 - 38
El maestro y la maestra se convierten en productores de saber que, al reconocer los procesos en los cuales trabajan in situ, se ubican como parte de un sistema viviente, haciendo parte de la creación y la re-creación; ubicándose como observadores auto-observantes distinguen entre lo preasignado en su conocimiento de enseñante y lo que acontece en su saber de práctica. El docente se da cuenta de que su condición humana es más plena cuando da campo a múltiples posibilidades, no solo de desarrollar instrumentalmente unos procesos, sino de desarrollar su capacidad de racionalidad, sensibilidad, emoción y pasión. Descubre que su experiencia, en la cual ocurre la vida, se da desde su capacidad de observar, analizar, conversar y actuar, por lo que entiende que la explicación producida es un proceso también de encontrarse consigo mismo desde aquello que hace y le da sentido a su vida. Da forma, en la práctica, a un proceso de formación colaborativa que construye comunidades de aprendizaje, saber, conocimiento, innovación y transformación.

Por ello, el maestro reconoce sus procesos de autoformación, los mismos que enriquecen su práctica y construyen una propuesta de aprendizaje y formación colaborativa, entendida como proceso de producción de saber en el encuentro colectivo con otras maestras y maestros. Al tiempo, construye una relación de igualdad con los sujetos que producen conocimiento y saber desde los acumulados disciplinarios de la pedagogía. En esa negociación cultural produce unos saberes propios que rompen con la homogeneización de los conocimientos relativos a la enseñanza, introduciéndolos en múltiples territorios pedagógicos que, a su vez, le demuestran que la pedagogía no es única y homogénea, sino múltiple y variada, y que él es un productor de ella.

Reconoce que la práctica no está separada de la experiencia, ya que ésta es una explicación fundamentada en ella, la cual acontece en la praxis del vivir y hacer su oficio. Por ello, debe disponer de las herramientas para que ese proceso se dé con características investigativas, reconociendo que no se da desde el simple sentido común. La experiencia es un producto. Las experiencias de este tipo, como la Expedición Pedagógica, proporcionan los elementos para registrar el asombro y la novedad. Ahí está el diario de campo, el cuaderno de notas, el relato, la pregunta, las historias de vida, las memorias ${ }^{42}$.

42 Para una ampliación ver La Caja de Herramientas del maestro expedicionario. En Expedición pedagógica nacional. (2001). Expedición pedagógica nacional. No. 2. Preparando el equipaje. Bogotá: Universidad Pedagógica Nacional. 
La explicación está en la práctica pero es diferente a la práctica, aun cuando ocurre desde ella. Las explicaciones, siendo importantes, no reemplazan lo que ellas explican, pues siempre están en movimiento, son recreadas por los desplazamientos que producen las realidades contextuales, los nuevos desarrollos conceptuales, la emergencia de nuevos procesos comunicativos, la llegada de nuevos campos tecnológicos y la emergencia de las nuevas formas de lo social.

El maestro y la maestra que se reconocen como productores de saber y conocimiento, deben dar cuenta, en su práctica, de esos nuevos desarrollos del mundo glocal en el que viven, para hacerlo utilizan la experiencia, reconociendo que la auto-observación es el punto de partida, ya que ella permite ver cómo y por qué se hace la práctica y sobre qué se fundamenta. El encuentro con otras pedagogías plantea preguntas sobre su propia práctica y, a su vez, les permitirá fundamentarla y entender múltiples realidades pedagógicas y, con ellas, múltiples experiencias. Luego las relacionará para producir su propia versión de aquello que constituye su práctica; así, el maestro entenderá que esos procesos han sido constituidos como fenómenos del dominio humano. Así es que se hace intelectual con un saber específico que lo dota de sentido e identidad en la sociedad.

Su producción es el resultado del proceso de innovación que le ha permitido formarse en el reconocimiento de su práctica, ésta ha sido reevaluada en el espejo analítico y crítico provisto por su encuentro con esas otras formas de hacer escuela y de ser maestro. Esta unión le hace renacer desde su reconocimiento de las experiencias de innovación de sus pares, que también están recreando la escuela y la pedagogía, generando una comunidad de sujetos prácticos-reflexivos que hacen de su quehacer un lugar de producción de saber y conocimiento, en un ejercicio de aprendizaje colaborativo y de autoformación que les permite apropiarse de su práctica desde otra perspectiva.

Es ahí cuando el maestro y la maestra que innovan encuentran que su ejercicio de la práctica a la experiencia se construye, y entienden que, más allá de los métodos, los enfoques y los paradigmas, hay múltiples pedagogías en ebullición. La interlocución les permite desarrollar un acto creativo en el que reconocen a los otros, pero a la vez les obliga a leer su propia práctica. Así, entienden que las pedagogías están hechas de: las nuevas realidades; de los contextos en que ellas se producen; de las nuevas teorías que replantean la forma tradicional del conocimiento; de los nuevos procesos comunicativos generados por los cambios de un mun- do social que se mueve en red; y de las manifestaciones de procesos tecnológicos en marcha. Para asimilar esta situación, los maestros encuentran múltiples caminos de respuesta creativa, de acuerdo al tipo de requerimiento que la práctica les va exigiendo, dando forma a las geopedagogías.

En este contexto, la práctica del maestro surge para: dar cuenta de un mundo en constante cambio; obtener respuestas desde su saber; constituir desde su quehacer las geopedagogías; y mostrar la realidad de las múltiples maneras de ser escuela y de ser maestro/maestra. Todo ello toma forma en el día a día de quienes innovan, su trabajo configura no solo la diferencia, sino la existencia de regiones pedagógicas que son posibles gracias a ese nuevo maestro que ha tomado su práctica para producir saber desde ella, convirtiéndola en experiencia y haciendo real el hecho de que ahora es capaz, luego de que se le había convertido en un instructor-enseñante y se le negó la posibilidad de producir saber, de encontrar un camino metodológico innovador, que le da otra identidad desde la experiencia entendida como práctica reflexionada y elaborada. Esto fue lo que sucedió en el Departamento del Cauca:

A pesar de sus condiciones, y justamente en medio de ellas, es que pudiéramos entender cómo ha emergido esa escuela-semilla, esa escuela-tierra, esa escuela-pueblo, esa escuela-raza, esa escuela-rotatoria, ese Quijote de Almaguer, ese rebelde encausado, esa mama grande, esa asamblea-rector, el etnodesarrollo, el cabildo educativo, las pedagogías de la resistencia, de la que heroicamente da testimonio el pueblo de Lerma, y muchas otras categorías que el equipo expedicionario ha logrado construir en un claro y desafiante acto de poder intelectual y, por supuesto, de poder político ${ }^{43}$.

\section{La pedagogía, campo en reconfiguración}

Ese maestro y esa maestra que han iniciado su marcha como productores de saber, reconocen que el saber y conocimiento están presentes en su práctica; también entienden el lugar de la experiencia. Con el conocimiento disciplinario y las técnicas para operar ese conocimiento en el aula, se hacen enseñantes, y con el saber pedagógico que les da una identidad como educadores y pedagogos, se reconocen en el doble ejercicio de su práctica

43 Expedición Pedagógica Nacional. (2006). Expedición Pedagógica Nacional. No. 7: Recorriendo el Cauca pedagógico. Bogotá: Universidad Pedagógica Nacional - Universidad del Cauca, p. 26. 
reflexionada, con la cual se han hecho conscientes de que: abandonar lo pedagógico es quitarle lo básico a su quehacer; pero, al tiempo, sin la disciplina este quehacer sería solo un instrumento de técnicas.

Esto también le permite al maestro comprender el poder del tiempo actual: aprovechando la reconfiguración de la pedagogía, propiciada por las modificaciones estructurales de una revolución productiva en marcha (fundada en el conocimiento, la ciencia, la tecnología, la información y la comunicación), replantea y reorganiza los elementos sobre los cuales estuvo construida la escuela de la modernidad: conocimiento, figuras de razón, subjetividades, soportes del hecho educativo, gestión e interacciones. Estas modificaciones exigen, en este momento, construir un proyecto educativo y escolar que responda a los desafíos actuales.

Sin embargo, el nuevo tipo de control reorganiza su ejercicio de poder, constituyendo un capitalismo cognitivo que a su vez busca, desde lo educativo, no solo construir las nuevas formas del cambio de época, sino también otro proyecto centrado en la despedagogización. Este proceso reduce la pedagogía al conocimiento disciplinario y a mínimos técnicos para instrumentalizar estándares y competencias, produciendo en el maestro una desposesión simbólica de su oficio, convirtiéndolo en un operador de enseñanza a través de técnicas, para lo cual ya no necesita concepción pedagógica. Por ello, el maestro recibe un adiestramiento en esas técnicas, así como en estándares y competencias, por parte de expertos externos, quienes tienen claros los objetivos y las estrategias de la educación. A maestros y maestras enseñarán esos procedimientos técnicos, para que, una vez apropiados, puedan practicarlos en el aula o en el espacio social en donde funge como educador ${ }^{44}$.

En estas condiciones históricas y contextuales es donde emerge el maestro que toma su práctica para convertirla en experiencia, reiterando la vigencia de la pedagogía en estos tiempos. Al afirmar la experiencia propiciada por la innovación, estos maestros reconocen, desde su ejercicio colaborativo, el despojo hecho a sus vidas por la "despedagogización" y apuestan, desde la reconfiguración, por trabajar desde otras bases que les permitan una identidad que no niegue ni aliene los elementos de su capacidad humana en ese mundo cambiante, y que por tanto los reconozca como hacedores prácticos capaces de teoría.

\footnotetext{
44 Para una ampliación de esta problemática, se recomienda revisar: Mejía, Marco Raúl. (2006). Globalizaciones y educaciones. Entre el pensamiento único y la nueva crítica. Bogotá: Ediciones Desde Abajo.
}

Por ello, los maestros y las maestras que asumen su práctica como campo de innovación y se empoderan de su quehacer, deciden disputar socialmente su condición de sujetos y de productores de saber y conocimiento, negándose a las nuevas formas curriculares que vuelven a realizar una separación entre trabajo manual e intelectual, las cuales nuevamente, y con discursos profesionalizantes (que en realidad son desprofesionalizadores), intentan hacer de ellos unos sujetos de enseñanza, unos operadores simbólicos de un capitalismo cognitivo que los despoja de su condición creadora.

Desde la afirmación de la pedagogía, el maestro hace política su práctica pedagógica, pues la entiende como un proceso en el cual su afirmación integral significa que la política está en su práctica, en el día a día de su vida. No le viene como un discurso social de afuera, sino que se integra en la configuración que debe realizar de su quehacer cotidiano, por ello, lo público de su vida se construye como resistencia al control del poder de estos tiempos. Desde su práctica-experiencia se convierte en un constructor de otros mundos posibles, en los cuales él encarna la nueva forma de la protesta, aquella que siempre debe contener una propuesta, para mostrar que es posible hacer su práctica de otra manera.

El maestro innovador ha dado el paso para entender que, desde su saber acumulado y saliendo del dualismo pedagogía-despedagogización, la educación es fuente de movimientos sociales, ya que presenta alternativas visibles en las enseñanzas de su día a día y permite reconocer una perspectiva metodológica plural que rompe los paradigmas cerrados. De igual manera, la práctica pedagógica de cualquier maestro innovador debe ser leída como política de la experiencia, lo cual empodera al aula, a las prácticas pedagógicas y a la condición del maestro, y llena de sentido las trabajos que se producen en el borde del sistema, los cuales dan paso a las geopedagogías que, al ser visibilizadas, exponen caminos para salir de los modelos cerrados, construyendo en el contexto específico esas pedagogías híbridas.

En este ejercicio expedicionario transformador emergen, en todo su sentido, los nuevos conflictos de la actualidad, visibles en ese maestro que ha dejado de ser portador para convertirse, desde la recuperación de su práctica-experiencia, en un agente que logra reconocer y concretar su saber desde un diálogo con la historia del conocimiento, y allí, entendiéndose como productor de saber, de vida con sentido, de agente de nuevas formas de geopedagogía y de nuevas formas de la política y de lo políti- 
co-pedagógico, comienza a conformar las nuevas instituciones y los nuevos movimientos sociales.

Este texto inició con una cita de Maturana, uno de los mayores representantes del conocimiento actual, y termina con las ideas de una maestra que, haciendo realidad el paso de la práctica a la experiencia vivida, como participante de la Expedición Pedagógica Nacional, sintetiza bellamente lo que hemos tratado de expresar: "Cuando uno vuelve, ya no es el mismo, cada lugar, así sea la propia casa, es distinto"

45 Maestra viajera del Eje Cafetero en: Expedición Pedagógica Nacional. No. 6: Con los dedos en la filigrana. Una lectura crítica a los tejidos metodológicos de la Expedición Pedagógica Nacional. Bogotá: Universidad Pedagógica Nacional, Fundación Restrepo-Barco. 2005, p. 83. 


\section{Referencias}

Adorno, T., et al. (1972). La disputa del positivismo en la sociología alemana. Barcelona: Grijalbo.

Barbier, Jean-Marie. (1996). Savoirs théoriques et savoirs d'action. París: Presses Universitaires de France.

Bateson, G. (1999). Pasos hacia una ecología de la mente. Buenos Aires: Lohlé-Lumen.

Bordieux, P. (1994). Raisons practiques. Sur la théorie de l'action. París: Seuil.

Bordieux, Pierre. (2000). Los usos sociales de la ciencia. Buenos Aires: Nueva Visión.

Cetrulo, R. (2001). Alternativas para una acción transformadora: educación popular, ciencias y política. Montevideo: Trilce, Instituto del Hombre.

Chalmers, A. F. (1987). Qué es esa cosa llamada ciencia. Madrid: Siglo XXI Editores.

De Souza, J. F. (2001). Atualidade de Paulo Freire. Contribuição ao debate sobre a educação na diversidade cultural. Recife: Edições Bagaço.

Deleuze, Guilles. (1987). Foucault. Barcelona: Paidós, p. 79.

Expedición Pedagógica Nacional. (2001). La Caja de Herramientas del maestro expedicionario. Expedición Pedagógica Nacional. No. 1: Huellas y registros. Bogotá: Universidad Pedagógica Nacional.

Expedición Pedagógica Nacional. (2001). Expedición pedagógica nacional. No. 2: Preparando el equipaje. Bogotá: Universidad Pedagógica Nacional.

EducAción y CIUdAd No 29 Julio - DiciemBre de 2015 ISSN 0123-0425 - PP 16 - 38
Expedición Pedagógica Nacional. (2003). Expedición Pedagógica Nacional. No. 4: Caminantes y Caminos. Expedición Pedagógica en Bogotá. Bogotá: Universidad Pedagógica, Fundación Restrepo Barco.

Expedición Pedagógica Nacional. (2005). Expedición Pedagógica Nacional. No. 6: Con los dedos en la filigrana. Una lectura crítica a los tejidos metodológicos de la Expedición Pedagógica Nacional. Bogotá: Universidad Pedagógica Nacional, Fundación Restrepo Barco.

Expedición Pedagógica Nacional. (2005). Expedición Pedagógica Nacional. No. 8: Recreando rutas y senderos pedagógicos en Valle, Cali y región norte del Cauca. Bogotá: Universidad Pedagógica Nacional, Universidad del Valle.

Expedición Pedagógica Nacional. (2005). Expedición Pedagógica Nacional. No. 9: Rutas de vida, maestros, escuelas y pedagogía en el Caribe colombiano. Bogotá: Universidad Pedagógica Nacional, Red pedagógica del Caribe.

Expedición Pedagógica Nacional. (2006). Expedición Pedagógica Nacional. No. 7: Recorriendo el Cauca pedagógico. Bogotá: Universidad Pedagógica Nacional, Universidad del Cauca.

FECODE. (2007- Diciembre). 25 años del Movimiento Pedagógico. Revista Educación y Cultura, No. 77. Bogotá: FECODE.

González de Alba, L. (2000). El burro de Sancho y el gato de Schrödinger. México: Paidós Amateur.

Grosso, J. L. (2005). Políticas de la diferencia. Interculturalidad y conocimiento. Trabajo presentado en el Seminario de FLAPE. 
Ibáñez, L. (1994). El retorno del sujeto. Santiago de Chile: Editorial Amerindia.

Kincheloe, J., y Maclaren, P. (2005). Rethinking critical theory and qualitative research. En Denzing, N., y Lincoln, Y. Handbook of Qualitative Research. Thousand Oaks. CA: Sage.

Kühn, T. (1972). La estructura de las revoluciones científicas. México: Fondo de cultura económica.

Lander, E. (s.f.). Ciencias sociales: saberes coloniales y eurocéntricos. Obtenido desde http://www.oei.es/salactsi/mato2.htm

Lucio, R. (1994). La construcción del saber y del saber hacer en pedagogía y Educación Popular. Revista Aportes, No.41. Bogotá: Dimensión Educativa.

Mariátegui, J. C. (1963). Ensayos de interpretación de la realidad peruana. Lima: Amauta.

Martín-Barbero, J. (1987). De los medios a las mediaciones. Barcelona: Editorial Gustavo Gili.

Martín-Barbero, J. (2007). ¿Razón técnica vs. Razón pedagógica? En Zuleta, M., Cubides, H., y Escobar, M. R. (Ed.). ¿Uno solo o varios mundos? Diferencia, subjetividad y conocimientos en las ciencias sociales contemporáneas. Bogotá: Universidad Central, IESCO, Siglo del Hombre.

Martínez, Miguel. (1997). El paradigma emergente. Hacia una nueva teoría de la racionalidad científica. México: Trillas.

Maturana, H. (1997). La objetividad, un argumento para obligar. Santiago de Chile: Editorial Dolmen.

Mejía, Marco Raúl. (2006). Globalizaciones y educaciones. Entre el pensamiento único y la nueva crítica. Bogotá: Ediciones Desde Abajo.

Mejía, Marco Raúl. (2007). El maestro y la maestra investigadora: fundamento de las geopedagogías. Bogotá [documento sin publicar].

Mejía, Marco Raúl. (2008). La Investigación como estrategia pedagógica. Una búsqueda por reconfigurar críticamente la educación en el cambio de época. La experiencia del Programa Ondas de Colciencias. Ponencia presentada en el IX Encuentro
Nacional de Jardines Infantiles: Los semilleros de potenciación, un camino hacia la inclusión. Manizales, Septiembre 18 al 20.

Mejía, Marco Raúl. (2008). La sistematización empodera y produce saber y conocimiento. Bogotá: Ediciones Desde Abajo.

Mejía, Marco Raúl. (2009-Junio). El maestro investigador: reconstructor de sentido profesional e identidad. Revista PACA, No. 1. Neiva: Universidad Surcolombiana.

Mejía, Marco Raúl. (2009-Agosto). Las pedagogías de la resistencia. Le monde diplomatique, Año VIII.

Mejía, Marco Raúl. (2011). La sistematización, una búsqueda de la episteme de las prácticas. Revista Diálogo de saberes.

Mejía, Marco Raúl. (2012). Educaciones y pedagogías críticas desde el sur. Cartografías de la Educación Popular. Bogotá: Editorial Magisterio.

Morin, Edgar. (2001). Introducción al pensamiento complejo. Barcelona: Gedisa.

Newton-Smith, W. H. (1987). La racionalidad de la ciencia. Barcelona: Paidós.

Nicolescu, Basarab. (s.f.). Manifiesto de la transdisciplinariedad. Obtenido el 9 de Septiembre de 2014, desde http://www.edgarmorin.org/libros-sin-costo/85-la-transdisciplinariedad-manifiesto. $\mathrm{html}$

Popper, Karl. (1958). La sociedad abierta y sus enemigos. Buenos Aires: Paidós.

Quijano, Aníbal. (1992). Raza, etnia, nación. Cuestiones abiertas en José Carlos Mariátegui y Europa. Lima: Amauta.

UNESCO. (1986). Conclusiones del simposio La ciencia y las fronteras del conocimiento. Venecia: ONU, UNESCO.

Wallerstein, Emmanuel. (2004). Abrir las ciencias sociales: Informe de la Comisión Gulbenkian para la reestructuración de las ciencias sociales. México: Siglo XXI.

Wittgenstein, L. (1957). Tractatus logico-philosophicus. Madrid: Revista de Occidente. 
RUTAS POSIBLES EN LA PRODUCCIÓN DE SABER Y CONOCIMIENTO: APUESTAS DE CIUDAD Y REGIÓN 